\title{
Mucosal enzyme activity for butyrate oxidation; no defect in patients with ulcerative colitis
}

\author{
E S Allan, S Winter, A M Light, A Allan
}

\begin{abstract}
Background-Butyrate is an important energy source for the colon and its metabolism has been reported to be defective in ulcerative colitis. One mechanism for defective butyrate metabolism in patients with ulcerative colitis could be an enzyme deficiency in the $\beta$-oxidation pathway of butyrate.
\end{abstract}

Aims-This study was undertaken to measure the activity of each enzyme involved in the $\beta$-oxidation pathway of butyrate in colonic epithelium.

Patients-Patients with ulcerative colitis $(n=33)$, Crohn's colitis $(n=10)$, and control subjects with colorectal cancer or diverticular disease $(n=73)$ were studied.

Methods-Analysis was carried out using fluorometric and spectrophotometric techniques on homogenised epithelial biopsy specimens.

Results-Significantly increased butyryl CoA dehydrogenase activity was found in mucosa from patients with ulcerative colitis $(33.2(28.3,38 \cdot 1) \mu \mathrm{mol} / \mathrm{g}$ wet weight/ min:mean (95\% CI)) compared with activity in mucosa from control patients (24.3 (20.9, 27.7) $\mu \mathrm{mol} / \mathrm{g}$ wet weight/ min:mean (95\% CI)) $p<0 \cdot 02$. No significant increase in activity of the enzymes butyryl-CoA synthetase, crotonase or hydroxybutyryl-CoA dehydrogenase was found in patients with ulcerative colitis. In contrast the mucosal thiolase activity was significantly lower in those patients with quiescent colitis $(3.21(2 \cdot 61,3.81) \mu \mathrm{mol} / \mathrm{g}$ wet weight/min:mean $(95 \%$ CI) when compared with control mucosa (5.69 (5.09, 6.29) $\mu \mathrm{mol} / \mathrm{g}$ wet weight/min:mean (95\% CI)) $p<0.001$. However, mucosal thiolase activity increases with the age of the donor patient and differences in the age range of the patient groups probably account for this finding.

Conclusions-This study shows no substantial deficiency of enzyme activity in the $\beta$-oxidation pathway of butyrate in the mucosa of patients with ulcerative colitis in histological remission.

(Gut 1996; 38: 886-893)

Keywords: short chain fatty acids, ulcerative colitis.

and Surgery, Good

Hope Hospital Trust,

West Midlands

A Allan

Correspondence to: Mr A Allan, Department of Surgery, Good Hope Hospital Trust, Wes Midlands B75 7RR.

Accepted for publication 13 December 1995

There is evidence that a metabolic defect within colonic epithelial cells could contribute to the pathogenesis of ulcerative colitis. Colonic epithelial cells absorb luminal butyrate and oxidise it to provide energy through the citric acid cycle. ${ }^{1-4}$ It was proposed by
Roediger that metabolism of luminal butyrate may be abnormal in patients with ulcerative colitis and that this abnormality may result in energy deficiency at the cellular level, ${ }^{5}$ thus contributing to the colitis.

By using in vitro metabolic studies, Roediger showed that butyrate was the fuel of choice for colonic epithelial cells compared with alternative fuels such as glucose or glutamine. ${ }^{6}$ Roediger also found that when colonic cells were studied from patients with ulcerative colitis these cells oxidised butyrate as an energy source to a lesser extent than cells from control tissues. ${ }^{5}$ Furthermore the inability of colonic epithelial cells to utilise butyrate occurred irrespective of the activity of the colitis, suggesting that the abnormality might represent a primary defect in the mucosa and not be secondary to the inflammation in the colonic tissue.

Ireland and Jewell ${ }^{7}$ and Chapman et $a l^{4}$ confirmed that utilisation of butyrate is decreased in colonic cells from patients with quiescent ulcerative colitis. But Chapman et al were unable to confirm an earlier finding by Roediger $^{2}$ that butyrate metabolism was greater in the descending colon compared with the ascending colon. ${ }^{8}$

Both groups found that 5 -aminosalicylic acid had no effect on butyrate metabolism in colonic epithelial cells from normal controls. ${ }^{79}$

In contrast Finnie et al, ${ }^{3}$ and Clausen et al ${ }^{10}$ were unable to demonstrate any defect of butyrate metabolism in mucosal biopsy specimens from patients with quiescent colitis compared with mucosa from normal controls. These authors suggested that the discrepancy with previous studies may have arisen either from the consequences of the epithelial cell isolation technique or because of the use of potentially toxic concentrations of butyrate. ${ }^{3}$

It is possible that abnormal butyrate oxidation may occur in the colonic epithelial cells of patients with quiescent ulcerative colitis. Such an abnormality may be of pathogenetic significance and therefore requires further study. This study set out to measure the activity of each enzyme involved in oxidation of butyrate (Fig 1).

\section{Methods}

\section{Tissue samples}

Prior to assay all tissue samples were coded so that the biochemist performing the assays was unaware of the disease group of the donor patient. It was not possible to assay all enzymes in the oxidation pathway in each 


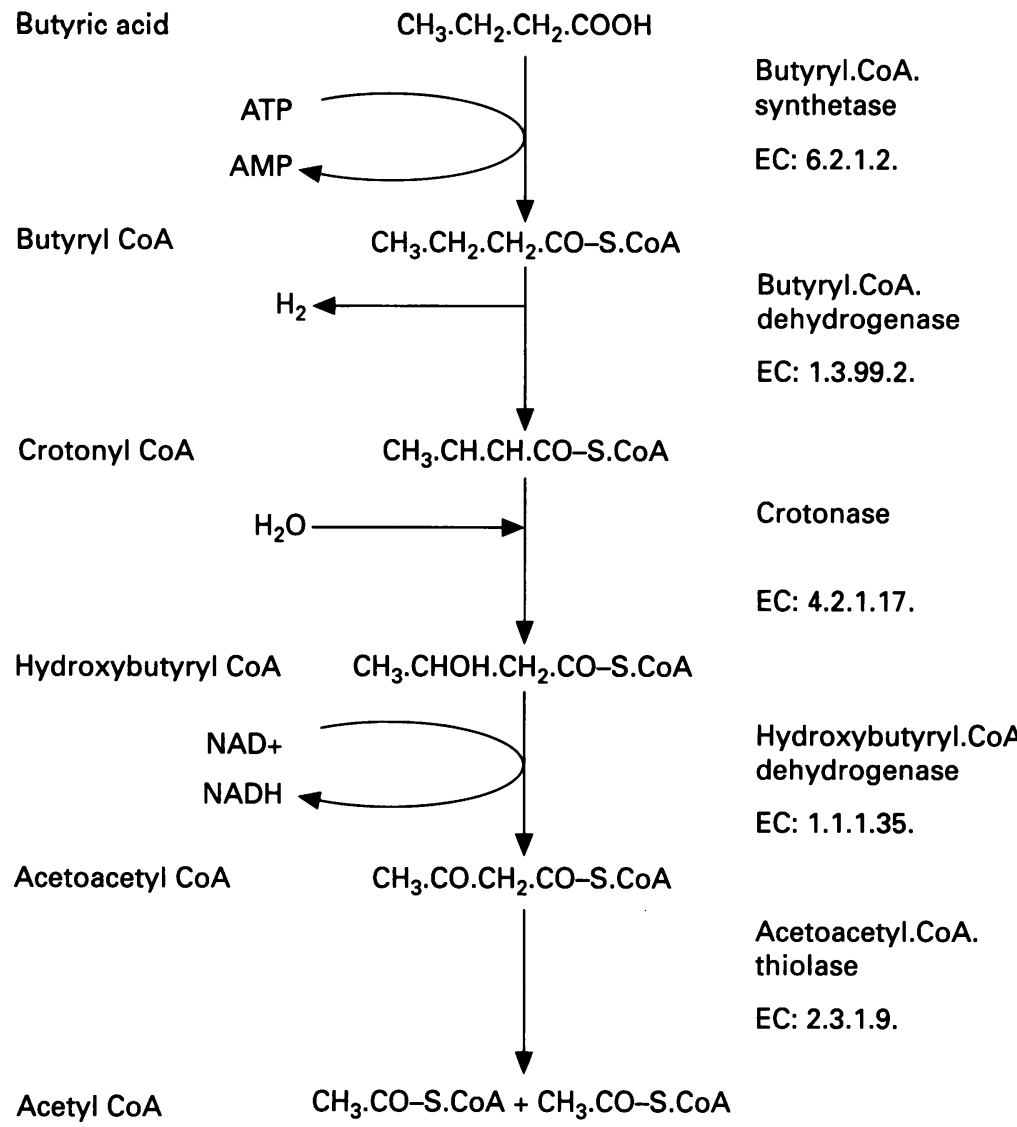

Figure 1: Pathway of $\beta$-oxidation of butyrate.

mucosal specimen. Therefore as many enzymes as possible were assayed depending on the amount of mucosa available for homogenisation from each patient. The effect of age, sex, or site of mucosa along the colon, or method of harvesting was assessed using normal mucosa.

\section{Sample preparation}

Samples of colorectal mucosa were transported to the laboratory in ice cold saline $(0.15 \mathrm{M}$ $\mathrm{NaCl}$ ). Samples were examined and excess moisture removed by blotting. Samples not for immediate analysis were snap frozen and stored at $-40^{\circ} \mathrm{C}$. Lamina propria lymphocytes were isolated and stored according to the method of Sachdev et al. ${ }^{11}$ Lymphocytes were thawed slowly at room temperature and enzymes assessed similarly to whole tissue samples.

Mucosa was removed from the bowel wall by scraping with the edge of a clean microscope slide and then weighed. Biopsy specimens were weighed and disrupted in entirety. Previously isolated lamina propria lymphocytes were weighed and then homogenised. All cells were homogenised in enzyme extraction buffers at a ratio of $100 \mathrm{mg} / \mathrm{ml}$ (wet weight/volume) by using an Omni 5000 hand held homogeniser at $4^{\circ} \mathrm{C}$.

\section{Subjects}

Mucosal specimens were taken from 73 subjects undergoing investigation or treatment for colorectal cancer $(n=69)$ or diverticular disease $(n=4)$. The median age of these patients was 67 (range 28-91) years and 39 were male. All mucosal specimens in these control patients were taken from a site at least $10 \mathrm{~cm}$ from any macroscopic abnormality and adjacent mucosal samples were histologically normal. Sixty of these mucosal specimens were taken at laparotomy and 13 at rigid sigmoidoscopy.

Mucosal specimens were taken from 33 subjects with ulcerative proctocolitis, median age 46 (range 18-83) years, 18 were men. Adjacent mucosal specimens were taken in each case for histological examination and assessment of severity of ulcerative colitis. Mucosal specimens were taken from 13 patients at laparotomy and 20 at rigid sigmoidoscopy.

Mucosal specimens were taken from 10 subjects with Crohn's colitis, median age 34 (21-67) years, two were men. All of these mucosal specimens were taken at laparotomy. All of these patients had coexisting small bowel Crohn's disease. The diagnosis of ulcerative or Crohn's colitis was established using conventional clinical, radiological, endoscopic, and histological criteria.

\section{Enzyme extraction}

Butyryl-CoA dehydrogenase and hydroxybutyryl-CoA dehydrogenase - mucosal homogenates were extracted into $50 \mathrm{mM}$ phosphate buffer ( $\mathrm{pH}=7 \cdot 0$ ) containing $0.3 \mathrm{mM}$ EDTA, $200 \mathrm{uM}$ phenylmethylsulphonyl fluoride, and $2 \mathrm{mM}$ dithiothreitol. Crude homogenate was reserved for hydroxybutyryl-CoA dehydrogenase assay. Homogenate for butyryl-CoA dehydrogenase assay was fractionated by addition of solid ammonium sulphate to $40 \% \mathrm{w} / \mathrm{v}$ with mixing for 30 minutes on ice and then centrifugation at $5000 \times g$ at $4^{\circ} \mathrm{C}$ for 15 minutes. The supernatant was assayed.

Crotonase, acetoacetyl-CoA thiolase, and butyryl-Co $A$ synthetase were extracted into 10 $\mathrm{mM}$ TRIS buffer $(\mathrm{pH}=7 \cdot 4)$ containing $1 \mathrm{mM}$ EDTA, $3 \mathrm{mM}$ magnesium chloride, and 300 $\mathrm{mM}$ sucrose.

\section{Cytological assessment of cell suspensions}

Before complete disruption by homogenisation, aliquots of mucosal cell suspensions from the normal colon of three patients were spread on glass slides and sprayed with polyethylene glycol, ethyl alcohol, and glacial acetic acid fixative and stained with Papanicolaou stain. The proportions of lymphocytes and epithelial cells in these preparations were then estimated microscopically for 10 high power $(\times 400)$ fields.

\section{Classification of mucosal samples from patients} with ulcerative proctocolitis

Routine haematoxylin and eosin stained paraffin wax sections were prepared from samples of mucosa adjacent to those used for assay. Inflammatory changes were classified using the criteria of Truelove and Richards ${ }^{12}$ (Appendix). Epithelial cell density was assessed using the grading system described by Goodman et al. ${ }^{13}$ 
TABLE I Enzyme activity in normal biopsy specimens. Enzyme is expressed in $\mu \mathrm{mol} g$ wet weight/minute. Numbers of samples and 95\% confidence limits are also shown

\begin{tabular}{|c|c|c|}
\hline Enzyme & Men & Women \\
\hline \multicolumn{3}{|c|}{ Butyryl-CoA synthetase } \\
\hline Mean & 0.058 & 0.049 \\
\hline Number & & \\
\hline $95 \% \mathrm{CI}$ & -0.062 to 0.178 & 0.019 to 0.079 \\
\hline \multicolumn{3}{|c|}{ Butyryl-CoA dehydrogenase } \\
\hline Mean & 21.97 & $25 \cdot 54$ \\
\hline Number & 6 & \\
\hline $95 \% \mathrm{CI}$ & $14 \cdot 77$ to $29 \cdot 2$ & $20 \cdot 7$ to 30.38 \\
\hline \multicolumn{3}{|l|}{ Crotonase } \\
\hline Mean & $9 \cdot 26$ & $9 \cdot 25$ \\
\hline Number & 16 & \\
\hline $95 \% \mathrm{CI}$ & $7 \cdot 2$ to $11 \cdot 3$ & 6.52 to 11.98 \\
\hline \multicolumn{3}{|c|}{ Hydroxybutyryl-CoA dehydrogenase } \\
\hline Mean & $4 \cdot 24$ & $4 \cdot 59$ \\
\hline Number & 34 & 30 \\
\hline $95 \%$ CI & 3.79 to 4.69 & $4 \cdot 1$ to $5 \cdot 08$ \\
\hline \multicolumn{3}{|l|}{ Thiolase } \\
\hline Mean & $5 \cdot 96$ & $5 \cdot 42$ \\
\hline Number & 34 & 31 \\
\hline $95 \% \mathrm{CI}$ & $5 \cdot 27$ to $6 \cdot 65$ & 4.4 to 6.44 \\
\hline
\end{tabular}

\section{Enzyme assays}

All chemicals and enzymes were purchased from Sigma Chemical Company UK. Assays were performed either spectrophotometrically using a Philips PU8720 spectrophotometer or fluorimetically using a Shimadzu RF-5001PC fluorimeter.

All enzyme assays were optimised for human colonic epithelial cells.

Butyryl-CoA synthetase (BuCoAs) was assayed according to the method of Lageweg et al. ${ }^{14}$ This enzyme catalyses the activation of butyrate to its CoA ester. The reaction was assessed by coupling the reaction to acyl-CoA oxidase and peroxidase. The rate of peroxide formation was assessed fluorimetrically. The intra-assay coefficient of variation was $9 \cdot 6 \%$.

Butyryl-Co $A$ dehydrogenase (BuCoADH) was assayed according to the method of Engel. ${ }^{15}$ $\mathrm{BuCoADH}$ catalyses the conversion of butyryl-CoA to crotonyl-CoA. The reaction
TABLE II Enzyme activity in $\mu$ mol/wet weight/min for control subjects in samples collected from rectal biopsy and surgical specimens from rectum, left colon, and right colon

\begin{tabular}{lcccc}
\hline & $\begin{array}{l}\text { Biopsy } \\
\text { specimen } \\
\text { Enzyme }\end{array}$ & \multicolumn{3}{l}{ Surgical specimen } \\
\cline { 3 - 5 } & (rectum) & Rectum & Left colon & Right colon \\
\hline Synthetase & 0.0783 & & 0.0375 & 0.0251 \\
BuCoA DH & 23.41 & & $32 \cdot 24$ & 21.50 \\
Crotonase & $8 \cdot 58$ & 7.90 & 8.45 & 13.26 \\
HoBuCoADH & $4 \cdot 19$ & $4 \cdot 53$ & $4 \cdot 16$ & $4 \cdot 71$ \\
Thiolase & $4 \cdot 13^{\star}$ & $6 \cdot 14$ & 5.44 & 6.75 \\
Protein & 3.71 & $4 \cdot 22$ & 3.62 & 3.53 \\
\hline
\end{tabular}

Statistical analysis of $\log _{10}$ transformed data shows no significant differences from synthetase, butyryl-CoA dehydrogenase, crotonase and hydroxybutyryl-CoA dehydrogenase. Thiolase crotonase and hydroxybutyryl-CoA dehydrogenase. Thiolase

between rectal biopsy samples and surgical samples. All

subsequent statistical analyses of thiolase activity were performed on like samples.

was assessed by coupling this reaction to dichlorophenolindophenol and phenazine methosulphate. The rate of decreasing absorbance was assessed spectrophotometrically at $600 \mathrm{nM}$.

Crotonase was assayed according to the method of Fong and Schultz. ${ }^{16}$ Crotonase catalyses the conversion of crotonyl-CoA to hydroxybutyryl-CoA. The formation of the magnesium complex was assessed spectrophotometrically at $280 \mathrm{~nm}$. The intra-assay and inter-assay coefficients of variation were $4 \%$ and $13 \%$ respectively.

Hydroxybutyryl-CoA dehydrogenase (Hobu$C o A D H)$ activity was measured according to the method of Fong and Schulz. ${ }^{17}$ HobuCoADH catalyses the conversion of hydroxybutyryl-CoA to acetoacetyl-CoA. However, in vitro the forward reaction rapidly equilibrates thus the reaction was assayed in the reverse direction. The rate of reaction resulting from nicotinamide adenine dinucleotide (NAD) formation was assessed spectrophotometrically at $340 \mathrm{~nm}$. The intra-assay and inter-
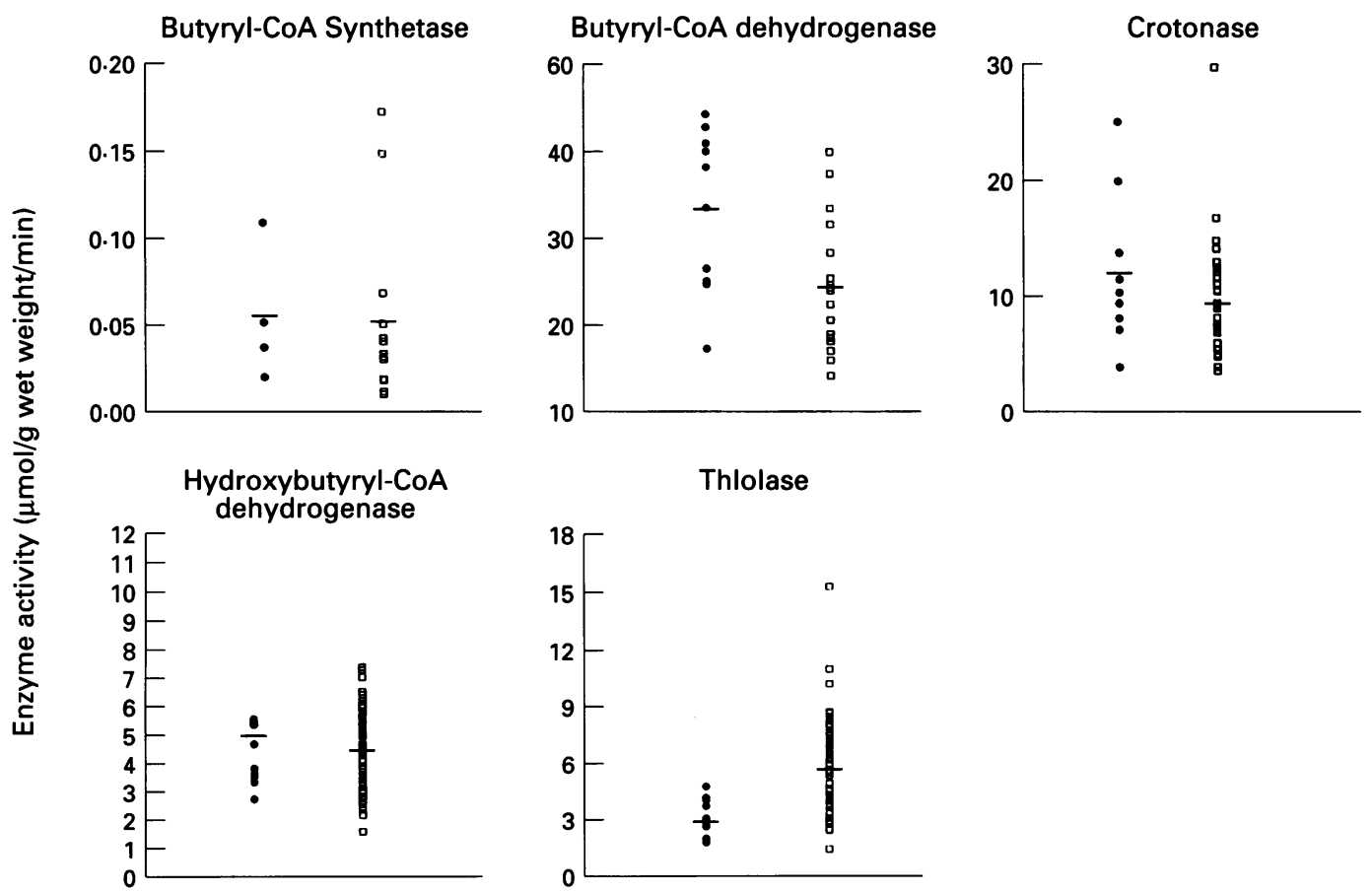

Figure 2: Comparison of enzyme activities between control subjects and ulcerative colitis patients classified as Truelove and Richards class 1. Control values are shown as $\square$ and ulcerative colitis samples as 0 . The mean enzyme activity is shown by horizontal line. 
TABLE III Variation of enzyme activity with age for control and ulcerative colitis samples

\begin{tabular}{|c|c|c|c|c|c|c|}
\hline \multirow[b]{2}{*}{ Enzyme } & \multicolumn{2}{|l|}{$30-50$} & \multicolumn{2}{|l|}{$51-70$} & \multicolumn{2}{|l|}{$71-90$} \\
\hline & Control & $U C$ & Control & $U C$ & Control & $U C$ \\
\hline $\begin{array}{l}\text { Synthetase } \\
\text { BuCoA DH } \\
\text { Crotonase } \\
\text { HoBuCoA DH } \\
\text { Thiolase }\end{array}$ & $\begin{array}{r}0.03 \\
29 \cdot 31 \\
6.63 \\
4.51 \\
3.43\end{array}$ & $\begin{array}{c}0.032 \\
28 \cdot 84 \\
8 \cdot 95 \\
3 \cdot 85 \\
3 \cdot 69\end{array}$ & $\begin{array}{c}0.052 \\
27 \cdot 25 \\
10 \cdot 76 \\
4 \cdot 33 \\
5 \cdot 74\end{array}$ & $\begin{array}{l}0.034 \\
24 \cdot 31 \\
11 \cdot 37 \\
3 \cdot 13 \\
2 \cdot 37\end{array}$ & $\begin{array}{c}0.067 \\
18.91 \\
7.97 \\
4.66 \\
6.12\end{array}$ & $\begin{array}{c}0.021 \\
25.45 \\
7.63 \\
2.96 \\
5.84\end{array}$ \\
\hline
\end{tabular}

assay coefficients of variation were $8 \cdot 2 \%$ and $16 \cdot 7 \%$ respectively.

Acetoacetyl-CoA thiolase (Thiolase) activity was assayed according to the method of Williamson et al. ${ }^{18}$ Thiolase catalyses the conversion of acetoacetyl-CoA to two acetyl-CoA units. The rate of reaction due to acetyl-CoA formation was assessed spectrophotometrically at $303 \mathrm{~nm}$. The intra-assay coefficient of variation was $4 \%$.

Protein concentration was determined using the method of Bradford. ${ }^{19}$ Protein concentrations in control samples, ulcerative colitis, and Crohn's samples were compared. No differences were seen between normal control samples and samples from patients with ulcerative colitis. Therefore no adjustment for protein concentration was made. In the case of Crohn's samples differences in protein

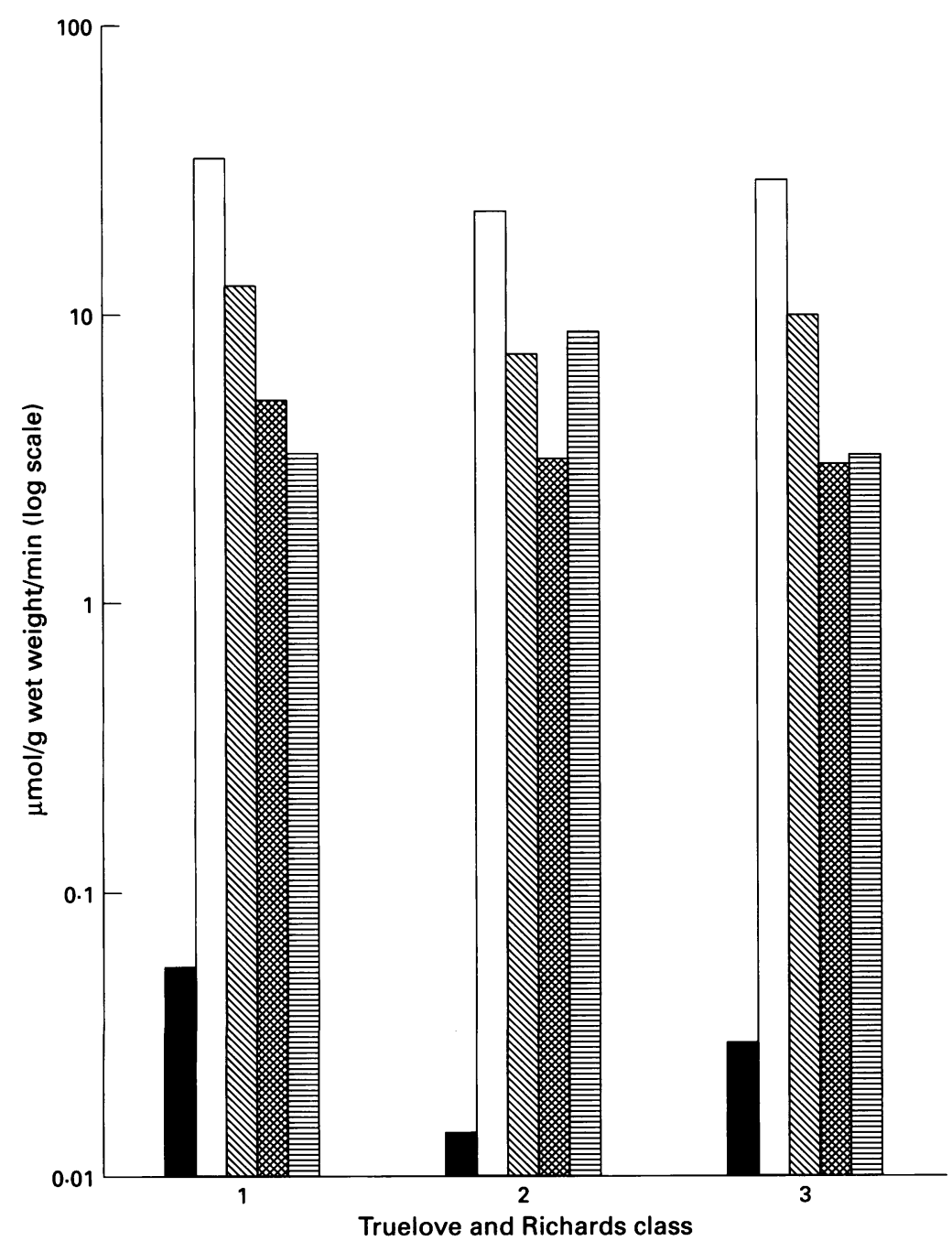

Figure 3: Comparison of enzyme activity between Truelove and Richards classes. ButyrylCoA synthetase ( $\square$ ), butyryl-CoA dehydrogenase ( $\square$ ), crotonase (\$) , hydroxybutyrylCoA dehydrogenase (国), thiolase (目). concentration with the control samples were observed and therefore all results were expressed per gram of protein.

\section{Statistical methods}

Comparisons in enzyme activity between groups of patients were assessed using an unpaired $t$ test with two tail $\mathrm{p}$ values on $\log _{10}$ transformations of the enzyme data. Other statistical tests are as indicated in the text.

\section{Ethics}

Approval for the study was given by the North Birmingham Research and Ethics Committees.

\section{Results}

Enzyme activity in histologically normal mucosa Table I summarises enzyme activity in normal biopsy specimens. No differences in enzyme activity were found between men and women for any of the enzymes tested (two sample $t$ test). One way analysis of variance showed no site related difference in enzyme activity between samples from the rectum, left or right colon. There was increased thiolase activity with age when patients were subdivided into three groups: those below 50 years, those between 50 and 70 years, and those over 70 years of age. Statistical analysis (one way analysis of variance) on $\log _{10}$ transformed data showed significant differences in enzyme activity between groups $(F=4 \cdot 83$ : $\mathrm{p}=0 \cdot 01)$. No other enzyme activity varied significantly with age. Thiolase activity also varied significantly between rectal biopsy and laparotomy samples with the biopsy specimens giving lower values (two sample $t$ test $\mathrm{p}=0.008$ ). Table II gives these results. All further comparisons were stratified into biopsy and rectal excision samples. No other enzyme activity varied with the mode of collection.

\section{Protein}

Fifty four specimens were assayed for protein content. The mean $(95 \% \mathrm{CI})$ protein concentration was $3.79(3.52,4.06) \mathrm{g} / \mathrm{g}$ wet weight tissue. No differences were seen across the age range of patients tested (45-91 years). Comparative analysis by site of origin of sample showed no differences between rectum, left colon or right colon (Table II).

\section{Enzyme activity in ulcerative colitis mucosa}

Butyryl-CoA synthetase - 18 patients donated biopsy specimens, eight were male and 10 were female. The median age was 55 years and the age range spanned 20 to 80 .

Butyryl-CoA dehydrogenase - 24 patients donated biopsy samples, 15 were male and nine were female. The median age was 39 years and the age range spanned 18 to 83 .

Crotonase - 20 patients donated biopsy specimens, 13 were male and seven female. 
The median age was 38 years and the age range spanned from 18 to 83 .

Hydroxybutyryl-CoA dehydrogenase - 24 patients donated biopsy specimens, 13 were male and 11 female. The median age was 39 years and the age range spanned 18 to 83 .

Thiolase - 20 patients donated biopsy samples, 13 were male and seven were female. The median age was 38 years and the age range spanned 18 to 72 .

\section{Comparison of enzyme activity in ulcerative} colitic mucosa with histologically normal mucosa For each enzyme studied a comparison was made between the enzyme activity in control biopsy specimens and the enzyme in Truelove and Richards ( $T$ and $R$ ) class 1 biopsy specimens (two sample $t$ test on $\log _{10}$ transformed data). The mean (95\% CI) butyryl CoA dehydrogenase activity ( $\mu \mathrm{mol} / \mathrm{g}$ wet weight/ min) in normal mucosa was $24.3(20.9,27 \cdot 7)$ $\mathrm{n}=18$ compared with $33 \cdot 2(28 \cdot 3,38 \cdot 1) \mathrm{n}=10$ in biopsy specimens of $T$ and $R$ class 1 $(\mathrm{p}=0.02)$. The mean thiolase activity was 5.69 $(5 \cdot 09,6 \cdot 29) \mathrm{n}=65$ in normal mucosa compared with $3.21(2.61,3.81) \mathrm{n}=9$ in samples of $T$ and $R$ class $1(p=0 \cdot 001)$. There was no significant difference in butyryl-CoA

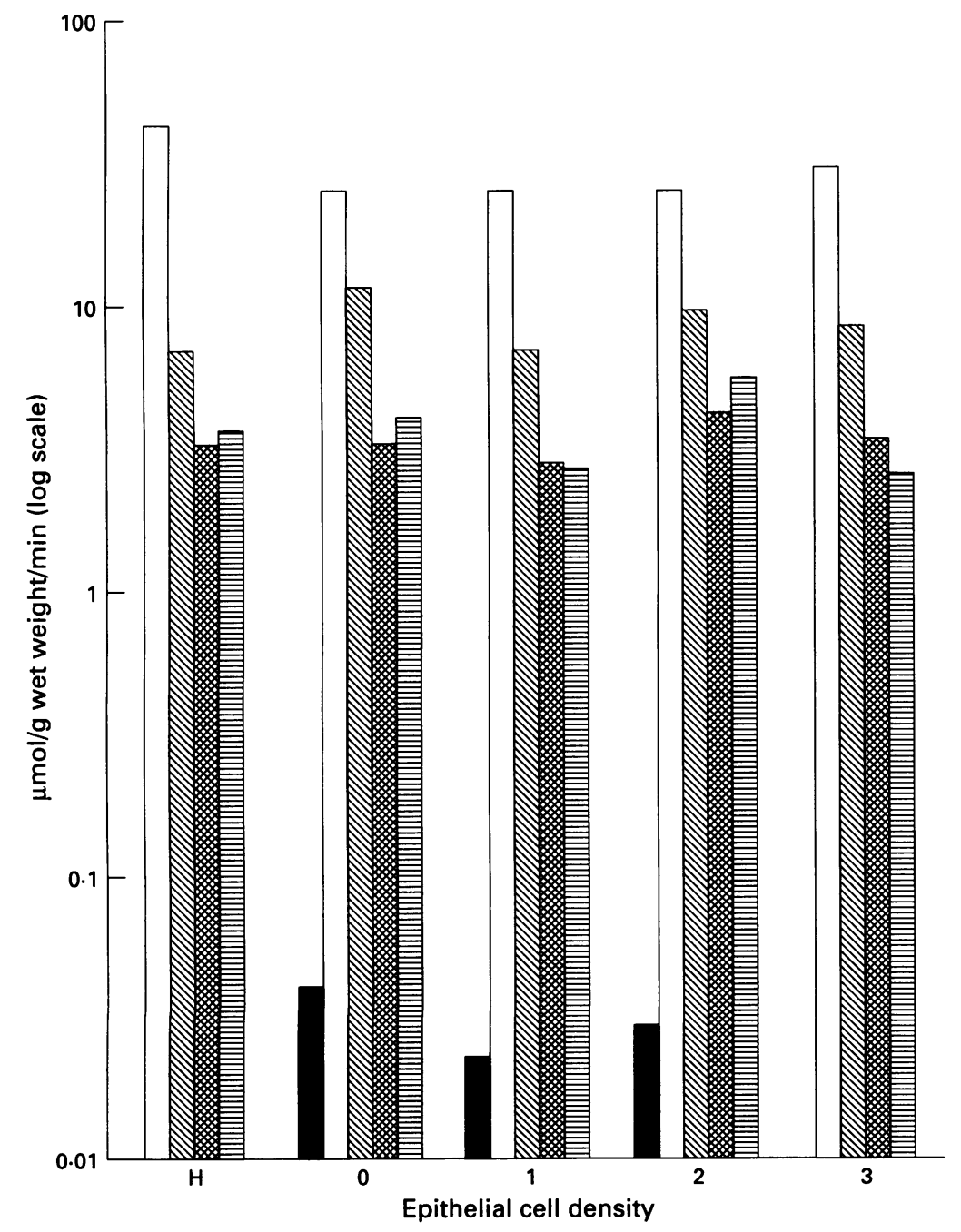

Figure 4: Comparison of enzyme activity in tissue classified according to epithelial cell density. Butyryl-CoA synthetase ( $\square$ ), butyryl-CoA dehydrogenase ( $\square$ ), crotonase $(\mathbb{N})$, hydroxybutyryl-CoA dehydrogenase ( thiolase (目). H=hypertrophied crypt. synthetase, crotonase, or hydroxybutyryl-CoA dehydrogenase activity between control and $\mathrm{T}$ and $R$ class 1 biopsy specimens (Fig 2).

The mean thiolase activity in $T$ and $R$ class 1 biopsy specimens was significantly lower than the mean thiolase activity in control samples. Within the $T$ and $R$ class 1 biopsy specimens the median age of the donor patients was 37 (range 28-62) years compared with a median age of 67 (range 28-85) years in patients with normal mucosa. In view of this the youngest nine control patients: median age 49 (range 28-52) years were selected from the control group and thiolase activity in these biopsy specimens was compared with the thiolase activity in the $T$ and $\mathrm{R}$ class 1 samples. No significant difference was found (two sample $t$ test on $\log _{10}$ transformed data $\mathrm{p}=0 \cdot 6$ ). Table III shows these data.

\section{Differences in enzyme activity in Truelove and \\ Richard classes}

Enzyme activity was compared between each of the three Truelove and Richards classes (one way analysis of variance on $\log _{10}$ transformed data). Butyryl-CoA dehydrogenase activity was significantly different between $T$ and $\mathbf{R}$ classes. Hydroxybutyryl-CoA dehydrogenase activity was also significantly different between $T$ and $R$ classes with enzyme activity falling with increasing inflammation in the adjacent mucosal samples (Fig 3 ).

\section{Correlation of enzyme activity with epithelial cell density}

Biopsy specimens from patients with ulcerative colitis were classified according to their epithelial cell density. There was a trend towards decreasing enzyme activity with decreasing cell density, but between the grades 1, 2, 3 there was no significant difference (Fig 4). No specimens were classified as class 4 .

\section{Correlation of enzyme activity with drugs taken by patient}

The mean enzyme activity in ulcerative colitis patients taking either oral or intravenous corticosteroids $(n=8)$ was compared with the enzyme activity in those patients taking neither topical nor systemic corticosteroids $(n=9)$. An unpaired $t$ test on the $\log _{10}$ transformed data showed no significant difference in any enzyme activity.

A similar analysis comparing the enzyme activity in patients taking any 5-aminosalicylic containing drug orally or rectally $(n=17)$ with the enzyme activity in those patients taking no 5-aminosalicylic containing drug either orally or rectally $(n=5)$ showed no significant differences.

Enzyme activity in the mucosa of patients with colonic Crohn's disease

Butyryl-CoA dehydrogenase - samples from nine patients were assayed for butyryl-CoA dehydrogenase activity. The mean activity was $1.33(0.83,1.83) \mu \mathrm{mol} / \mathrm{g}$ protein $/ \mathrm{min}$. 


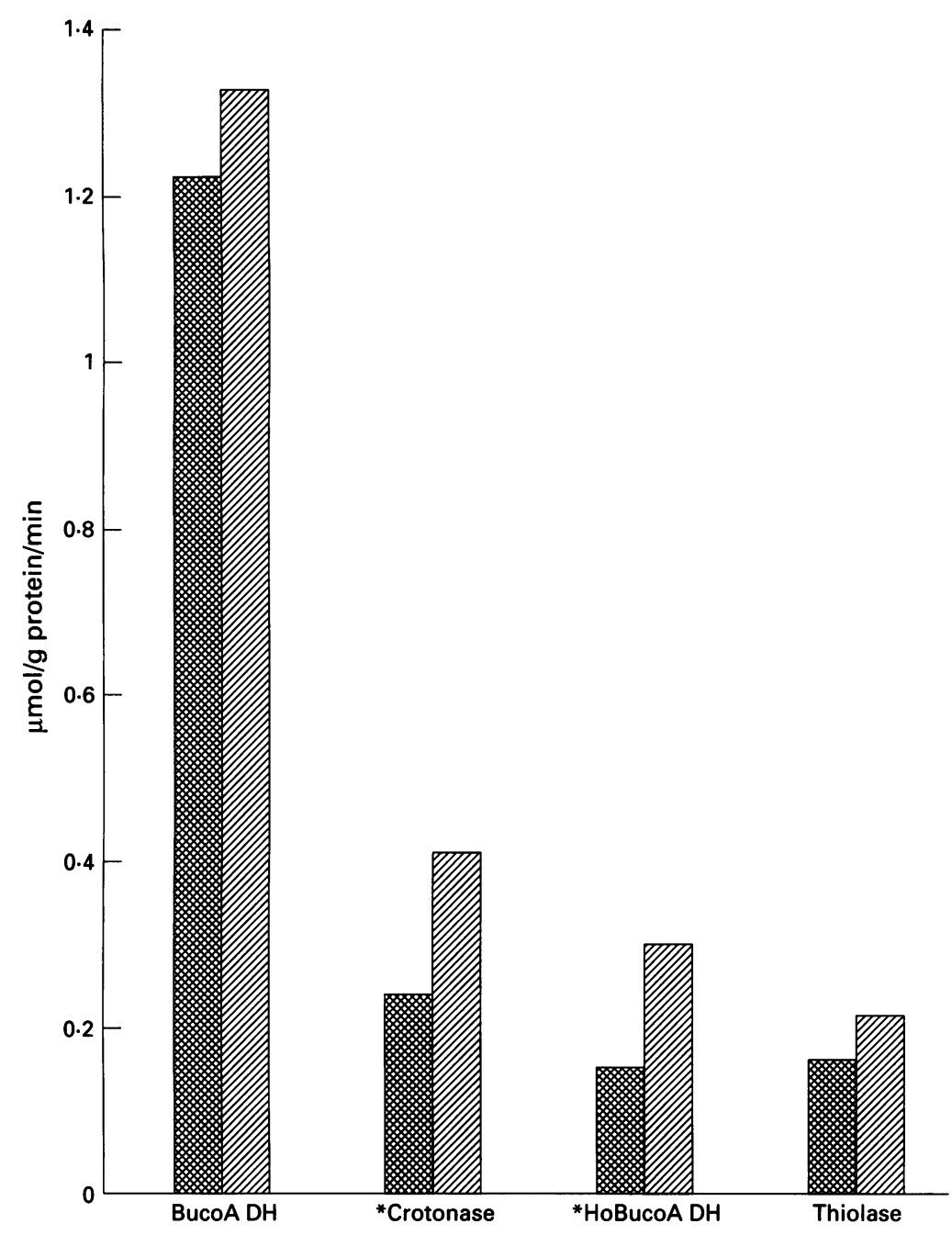

Figure 5: Comparison of enzyme activity in Crohn's and control tissue. The enzyme activity is expressed in $\mu \mathrm{mol} g \mathrm{~g}$ protein/minute. Crohn's disease (ख), control (ख). ${ }^{\star} p<0.05$ unpaired $\mathrm{t}$ test on $\log _{10}$ transformed data.

Crotonase - samples from nine patients were assayed for crotonase activity. The mean activity was $0.41(0.25,0.57) \mu \mathrm{mol} / \mathrm{g}$ protein $/ \mathrm{min}$.

Hydroxybutyryl-CoA dehydrogenase - 10 patients' samples were assayed for hydroxybutyryl-CoA dehydrogenase activity. The mean enzyme activity was $0.3(0.22,0.38) \mu \mathrm{mol} / \mathrm{g}$ protein/min.

Thiolase - samples from 10 patients were assayed for thiolase activity. The mean activity was $0.21(0.09,0.33) \mu \mathrm{mol} / \mathrm{g}$ protein $/ \mathrm{min}$.

Comparison of Crohn's and control tissue Comparison of Crohn's and control tissue showed similar activities in the enzymes butyryl-CoA dehydrogenase and thiolase. In the case of crotonase and hydroxybutyryl-CoA dehydrogenase enzyme activities were significantly higher in Crohn's tissue than the controls (Fig 5) (unpaired $t$ test on $\log _{10}$ transformed data).

\section{Lamina propria lymphocytes}

Homogenates of lamina propria lymphocyte prepared from normal, ulcerative colitis, and Crohn's colonic tissue were assayed for a range of enzyme activities. No butyryl-CoA synthetase activity was measurable in lamina propria lymphocytes from control, ulcerative colitis, or Crohn's disease patients. Measurable enzyme activity was seen in each tissue type for the enzymes butyryl-CoA dehydrogenase, Crotonase, hydroxybutyryl-CoA dehydrogenase, and thiolase (Fig 6). No differences in enzyme activities were seen between the tissue types except that higher hydroxybutyryl-CoA dehydrogenase activity was seen in ulcerative colitis lymphocytes. Cytological studies show that less than $10 \%$ of cells in the homogenate were lamina propria lymphocytes the remaining $90 \%$ being colonic epithelial cells.

\section{Discussion}

This study represents the first attempt to measure the activity of the enzymes responsible for the oxidation of butyrate in human colonic epithelial tissue. All enzymes were detected and measured although the dehydrogenation step mediated by hydroxybutyrylCoA dehydrogenase equilibrates so rapidly in vitro that it requires assay in the reverse direction. One unexpected finding was an increase in thiolase activity with increasing age. The mechanism for this phenomenon remains unclear. The increase in thiolase activity with increasing age might explain the apparent difference in thiolase activity between control and colitic tissue. No other important variations of enzyme activity within normal colon were noted with age, sex, or position around the colon. There was a significantly lower thiolase activity in endoscopic biopsy specimens compared with operative specimens.

In ulcerative colitis each of the enzymes butyryl-CoA synthetase, butyryl-CoA dehydrogenase crotonase, and hydroxybutyryl-CoA dehydrogenase showed increased activity in Truelove and Richards class 1 mucosa compared with that found in control mucosa. But only for butyryl-CoA dehydrogenase did this rise reach significance. There was an inverse relation between mucosal inflammation and enzyme activity. In the most severely affected mucosa (Truelove and Richards 3) there was a tendency for activity to increase once again. For butyryl-CoA and hydroxybutyryl-CoA dehydrogenases these changes reach significance. One possible explanation for this finding is that although there is probably a generalised depression in enzyme activity with increasing damage to epithelial cells by the inflammatory process, this depression may be offset by increased crypt cell production. Crypt cell production is known to increase with increasing disease activity in the mucosa of patients with ulcerative colitis. ${ }^{20}$ Thus enzyme activity in each particular Truelove and Richards class may depend on a balance between inflammation and cell production.

For thiolase activity, there was a different change in enzyme activity with a significant fall in activity in Truelove and Richards class 1 compared with control biopsy specimens. This at first sight could be interpreted as an abnormality with potential significance for the pathogenesis of ulcerative colitis. Further assessment shows that this finding is almost 


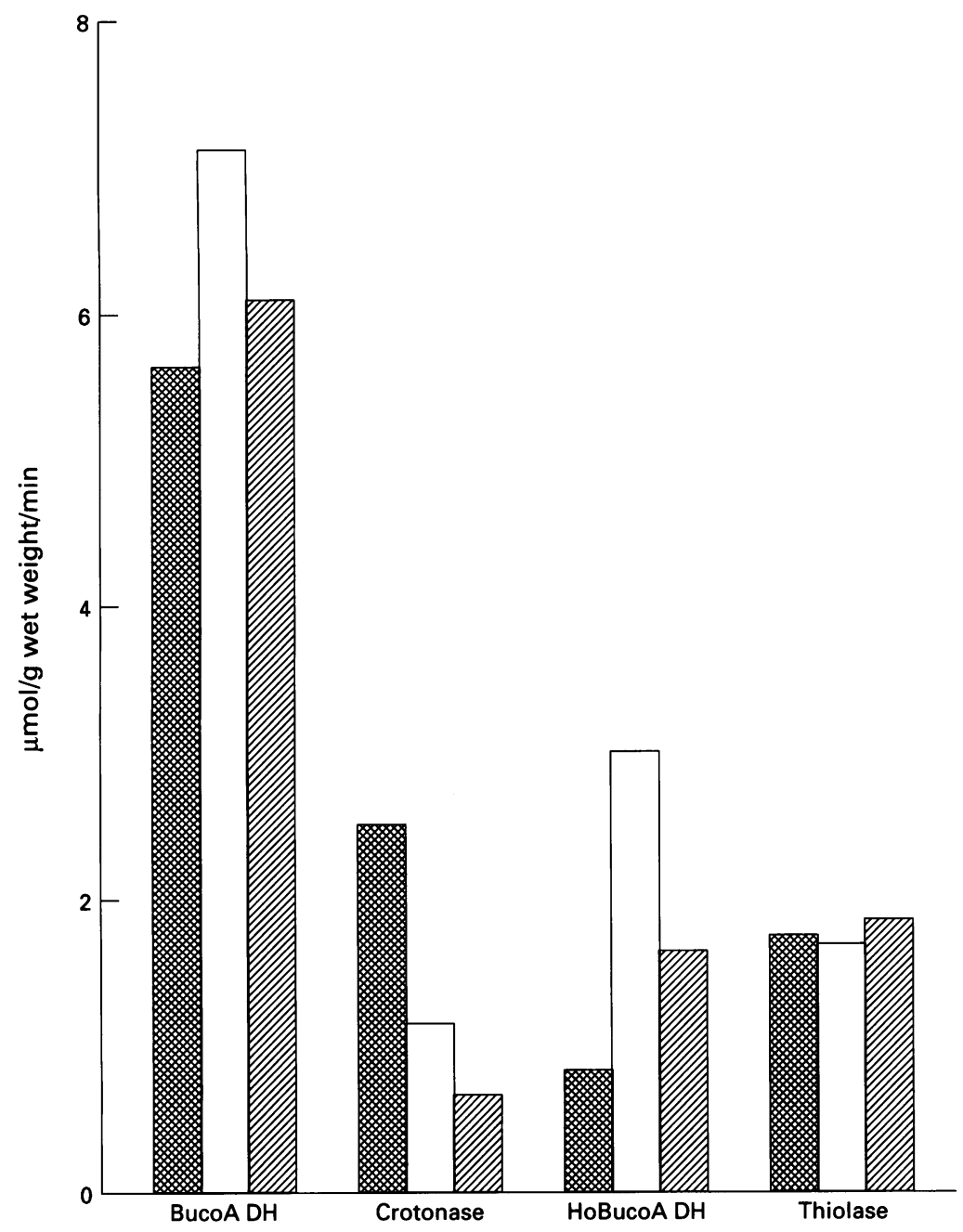

Figure 6: Enzyme activities in lamina propria lymphocytes from control (ख), ulcerative colitis ( $\square)$, and Crohn's disease ( $\square$ ) tissues. Enzyme activity is expressed as $\mu \mathrm{mol} g$ wet weight tissue/min.
Enzyme activity in colonic mucosa from patients with Crohn's colitis was raised compared with that from the mucosa of control subjects. This rise in activity was significant for the enzymes butyryl-CoA dehydrogenase and thiolase. This rise in activity mirrors the increased activity seen in Truelove and Richards class 1 mucosa from patients with ulcerative colitis. It probably occurred because of selection of the least inflamed tissue in the colon for assay. Previous studies of the enzyme glucosamine synthetase ${ }^{13}$ report a rise in the activity of this enzyme in the mucosa of patients with Crohn's colitis even at sites distant from the macroscopically evident disease. The rise in enzyme activity found in mucosa from patients with Crohn's colitis is probably not caused by an increased cell turnover in the Crohn's tissue because cell proliferation in rectal biopsy specimens from patients with rectal Crohn's disease is normal irrespective of the degree of inflammation in the rectum. ${ }^{21}$ It seems more probable that the disease process triggers a generalised reactive increase in the activity of many intracellular enzymes. This finding suggests that the observed rise in glucosamine synthetase activity in patients with Crohn's colitis is part of a more widespread response to inflammation in the colonic epithelial cell.

This study used biopsy specimens and not epithelial cell preparations to study colonic epithelial cell enzyme activity and therefore consideration must be given to sources of enzyme activity within the samples but not arising from the colonic epithelial cells themselves. Although colonic wall muscle does not metabolise butyrate ${ }^{3}$ the mucosal homogenate used for enzyme assay contained a mixture of both colonic epithelial cells and lamina proprial lymphocytes. Cytological assessment of these cell mixtures suggested that laminal proprial lymphocytes accounted for only $10 \%$ of the cells in the mixture. Further studies on isolated laminal proprial lymphocytes showed a small but detectable enzyme activity from these cells. This activity was similar irrespective of whether the cells were from control subjects or patients with inflammatory bowel disease. They are therefore likely to have made a minimal but relatively constant contribution to the total enzyme activity in the homogenates irrespective of the source of the specimens.

In conclusion, this study suggests that if abnormalities of butyrate metabolism occur in the colonic epithelium of patients with ulcerative colitis then the mechanism of this abnormality does not entail decreased enzyme activity in the $\beta$-oxidation pathway for butyrate. None the less an abnormality of butyrate metabolism in patients with ulcerative colitis remains possible. It seems unlikely that supply of butyrate to colonic epithelial cells is ever in danger because studies of colonic luminal bacterial flora in patients with ulcerative colitis show few changes. ${ }^{22}$ In addition absorption of butyrate in the remission phase of the disease is no different from absorption in control subjects. ${ }^{23}$ However, other abnormalities of intracellular butyrate colonic epithelial cells from normal controls. This study complements this finding by suggesting that neither corticosteroid nor 5-aminosalicylic acid treatment have any effect on the enzyme activity of the oxidation pathway of butyrate. 
metabolism may occur such as abnormal intracellular transport of butyric acid, alteration of mitochondrial oxidation or abnormal incorporation of butyrate products into the citric acid cycle for energy production.

This study was supported by a grant from the West Midlands Regional Health Authority and the Sutton Municipal Charities. The isolated lamina proprial lymphocytes were a generous gift from Dr D P Jewell, The Radcliffe Infirmary, Oxford. Dr P J Hanson, Department of Pharmaceutical Sciences, University of Aston gave invaluable advice on aspects of the enzymes assays. Mrs J H Plant typed the manuscript.

1 Cummings JH, Pomare EW, Branch WJ, Naylor CPE, MacFarlene GT. Short chain fatty acids in the human large intestine, portal, hepatic and venous blood. Gut 1978; 28: 1221-7.

2 Roediger WEW. Role of anaerobic bacteria in the metabolic welfare of the colonic mucosa in man. Gut 1980; 21: 793-8.

3 Finnie IA, Taylor BA, Rhodes JM. Ileal and colonic epithelial metabolism in quiescent ulcerative colitis: increased glutamine metabolism in distal colon but no defect in butyrate metabolism. Gut 1993; 34: 1552-8.

4 Chapman MAS, Grahn MF, Boyle MA, Hutton M, Rogers $\mathrm{J}$, Williams NS. Butyrate oxidation is impaired in the colonic mucosa of sufferers of quiescent ulcerative colitis. Gut 1994; 35: 73-6.

5 Roediger WEW. The colonic epithelium in ulcerative colitis: an energy deficiency disease? Lancet 1980; ii: 712-5.

6 Roediger WEW. The utilisation of nutrients by isolated epithelial cells of the rat colon. Gastroenterology 1989; 83: epithelia.

7 Ireland A, Jewell DP. 5-aminosalicylic acid (5-ASA) has no effect on butyrate metabolism in human colonic epithelial cells. Gastroenterology 1989; 102: A176.

8 Chapman MAS, Grahn MF, Giamondo P, O'Connell PR, Onwu $\mathrm{D}$, Hutton $\mathrm{M}$, et al. A new technique to measure mucosal metabolism and its use to map substrate utilisation in the healthy human large bowel. Br f Surg 1993; 80: 445-9.

9 Chapman MA, Grahn MF, Williams NS. 5-aminosalicylic acid increases colonic mucosal oxidation of glucose [Abstract]. Br 7 Surg 1993; 80: 648.

10 Clausen MR, Mortensen PB. Kinetic studies of coloncyte metabolism of short chain fatty acids and glucose in metabolism of short chain fatty acids and glucose

11 Sachdev GK, Dalton HR, Hoang P, Dipaglo MC, Crotty B, Jewell DP. Human colonic intraepithelial lymphocytes suppress in-vitro immunoglobin synthesis by autologous peripheral blood lymphocytes and lamina propria lymphocytes. Gut 1993; 34: 257-63.

12 Truelove SC, Richards WCD. Biopsy studies in ulcerative colitis. BMF 1956; 1: 1315-8.

13 Goodman MJ, Kent PW, Truelove SC. Glucosaminesynthetase activity of the colonic mucosa in ulcerative colitis and Crohn's disease. Gut 1977; 18: 219-28.

14 Lageweg W, Steen I, Tager JM, Wanders RJA. A fluorimetric assay for Acyl-CoA synthetase activities. Analyt Biochem 1991; 197: 384-8.
15 Engel P. Butyryl-CoA dehydrogenase from Megasphaera elsdenii, Methods Enzymol 1981; 71: 359-66.

16 Fong JC, Schulz H. Purification and properties of pig heart crotonase and the presence of short chain and long chain enoyl Coenzyme A Hydratases in pig and guinea pig tissues. F Biol Chem 1977; 252: 542-7.

17 Fong JC, Schulz $\mathrm{H}$. On the rate - determining step of fatty acid oxidation in heart. Inhibition of fatty acid oxidation acid oxidation in heart. Inhibition of fatty acid oxidation

18 Williamson DH, Bates MW, Page MA, Krebs HA. Activities of enzymes involved in acetoacetate utilisation Activities of enzymes involved in acetoacetate utilisation

19 Bradford $M H$. A rapid and sensitive method for the quantitation of microgram quantities of protein utilising the principle of dye binding. Analyt Biochem 1976; 72: 248-54.

20 Allan A, Bristol JB, Williamson RCN. Crypt cell production rate in ulcerative proctocolitis: differential increment in remission and relapse. Gut 1985; 26: 999-1003.

21 Winslet MC, Allan A, Poxon V, Youngs D, Keighley MRB. Faecal division for Crohn's colitis: a model to study the role of the faecal stream in the inflammatory process. Gut 1994; 35: 236-42.

22 Keighley MRB, Arabi Y, Dimock F, Burdon DW, Allan RN. The influence of inflammatory bowel disease on RN. The influence of inflammatory bowel dise
intestinal microflora. Gut 1978; 19: 1099-104.

23 Roediger WEW, Hayworth M, Willoughby P, Piris J, More A. Luminal ions and short chain fatty acids as markers of functional activity of the mucosa in ulcerative colitis. f Clin Pathol 1982; 35: 323-6.

Appendix Summary of Truelove and Richards classification for histological severity of ulcerative colitis

No significant inflammation

Inflammation Nil

Crypt abscesses Absent

Epithelium Intact

Gland architecture Glands reduced in number Stunted and atrophic

Mild to moderate inflammation

Inflammation Increased chronic inflammatory cell Mild increase in neutrophils Variable intensity

Crypt abscesses Epithelium

Occasional
Increased proliferation Increased proliferation

Gland architecture Irregular shape and density

Severe inflammation Inflammation

Chronic inflammatory cell infiltrate

Crypt abscesses

Plentiful+erosions of crypt epithelium

Inflammation extending into lamina propria

Epithelium

Small breaches and erosions Irregular and often cuboid cells adjacent to erosions

Gland architecture Markedly irregular in density and shape with gland destruction 